\title{
THE RANGE OF PROBLEMS IN SARMATIAN STUDIES AND ARCHAEOLOGICAL COMPLEXES IN SOUTHERN KAZAKHSTAN
}

\author{
Aleksandr N. Podushkin \\ South Kazakhstan State Pedagogical Institute, Shymkent, Kazakhstan
}

\begin{abstract}
The paper is devoted to a comprehensive analysis of materials from the catacomb monuments of the Arys culture of Southern Kazakhstan in the $1^{\text {st }}$ century BC $-4^{\text {th }}$ century AD in the context of Sarmatian studies and preserving the ethnocultural traditions of European and Asian Sarmatians in the region on the basis of archaeological data. We describe the catacomb funerary structures of two types in a constructive context: $T$-shaped and $\Gamma$ - shaped catacombs with long narrow-transverse dromos (a path or a corridor leading to the funerary chamber of the tomb or mound), as well as T-shaped catacombs with dromoses with shaft collars. We determine the role of these funerary structures in rituals of nomads and the functions of funeral attribution - ceramics and signs depicted on it.

Special attention is paid to the issues of chronology in the light of new archaeological sources. Several key chronological indicators have been identified, including bronze disc-shaped mirrors with a handle-pin, silver and bronze fibulae-fasteners, gold earrings in a polychrome style, weapons (a dagger with an annular solid pommel and straight bar-like crosshair), Egyptian faience ware, silver buckles in animal style.

Other direct and indirect chronological indicators include ceramic censers, as well as numismatic and paleolinguistic materials. We are talking about the discovery of several significant findings in the same cultural layer of the Kangyu period at the same time: the khum with the Sarmatian tamga sign, the Kushan copper coin of the ruler Wim I Takto and the fragment of the Kultobin (Sodi, Kangyu) letter on the ceramic bricks-tables. The data given, the corresponding chronological calculations and ethno-cultural interpretations allow us to speak about the presence of Sarmatians in the territory of the region of Southern Kazakhstan in the $1^{\text {st }}-3^{\text {rd }} \mathrm{cc}$. AD., who at that time integrated into the state of Kangyu.
\end{abstract}

Key words: Southern Kazakhstan, Arys culture, catacomb burials, signs on ceramics, Sarmatians, Kangyu.

Citation. Podushkin A.N. The Range of Problems in Sarmatian Studies and Archaeological Complexes in Southern Kazakhstan. Vestnik Volgogradskogo gosudarstvennogo universiteta. Seriya 4, Istoriya. Regionovedenie. Mezhdunarodnye otnosheniya [Science Journal of Volgograd State University. History. Area Studies. International Relations], 2018, vol. 23, no. 3, pp. 189-205. (in Russian). DOI: https://doi.org/10.15688/jvolsu4.2018.3.17

УДК 902“634”(477,7)

ББК Т4(43УКР7,5)24

Дата поступления статьи: 14.02.2018

Дата принятия статьи: 10.04.2018

\section{САРМАТСКАЯ ПРОБЛЕМАТИКА И АРХЕОЛОГИЧЕСКИЕ КОМПЛЕКСЫ КАТАКОМБ ЮЖНОГО КАЗАХСТАНА}

\author{
Александр Николаевич Подушкин \\ Южно-Казахстанский государственный педагогический институт, г. Шымкент, Республика Казахстан
}

\footnotetext{
$\infty$ Аннотация. Публикация посвящена комплексному анализу материалов из катакомбных памятников 尺े арысской культуры Южного Казахстана I в. до н. э. - IV в. н. э. в контексте сарматской проблематики и фٔ. фиксации этнокультурных традиций европейских и азиатских сарматов в регионе по археологическим данным. Приводится характеристика катакомбных погребальных сооружений двух типов в конструктивном контексте: Т-образные и Г-образные катакомбы с длинным узкотраншейным дромосом, а также Т-образные катакомбы с дромосом, с заплечиками; определяется роль, участие этих погребальных сооружений в обрядовых действиях номадов и функции погребальной атрибуции (керамика, знаки на ней).

Отдельно освещены вопросы хронологии в свете новых археологических источников. Выделены нес сколько ключевых хроноиндикаторов, в числе которых бронзовые дисковидные зеркала с ручкой-штырем,
} 
серебряные и бронзовые фибулы-застежки, золотые серьги в полихромном стиле, оружие (кинжал с кольцевым навершием и прямым брусковидным перекрестием), изделия из египетского фаянса, серебряная пряжка в зверином стиле.

В качестве других прямых и косвенных хроноиндикаторов привлечены керамические курильницы, а также нумизматические и палеолингвистические материалы. Речь идет об обнаружении в одном культурном слое кангюйского периода одновременно нескольких значимых находок: хума с сарматским знакомтамгой, кушанской медной монеты правителя Вима I Такто и фрагмента культобинского (согдийского, кангюйского) письма на керамических кирпичах-таблицах. Приведенные данные, соответствующие хронологические выкладки и этнокультурные интерпретации позволяют говорить о присутствии на территории региона Южного Казахстана в I - III в. н. э. сарматов, которые интегрировались в это время в состав государства Кангюй.

Ключевые слова: Южный Казахстан, арысская культура, катакомбные погребения, знаки на керамике, сарматы, Кангюй.

Цитирование. Подушкин А. Н. Сарматская проблематика и археологические комплексы катакомб Южного Казахстана // Вестник Волгоградского государственного университета. Серия 4, История. Регионоведение. Международные отношения. - 2018. - Т. 23, № 3. - С. 189-205. - DOI: https://doi.org/10.15688/ jvolsu4.2018.3.17

До недавнего времени регион Южного Казахстана в историко-археологическом аспекте практически не связывался с сарматским миром. Сарматская проблематика в том варианте, как она высвечивается в настоящее время (погребальные памятники, весомые археологические комплексы, иные признаки, позволяющие прямо и косвенно связывать материалы с культурными и этническими традициями азиатских сарматов), обозначилась в 80-е гг. ХХ столетия, когда в регионе Южного Казахстана активно стали исследоваться археологические объекты, имеющие отношение к государству Кангюй (Канцзюй).

В результате была выделена арысская археологическая культура Южного Казахстана IV в. до н. э. - VI в. н. э. как научная категория, фиксирующая устойчивые системы традиций в материальной сфере на большой группе памятников зоны «Средняя Сырдарья - горы Каржантау, Каратау - бассейн p. Арысь». Сейчас исследователи имеют полное представление о памятниках и специфическом блоке признаков культуры в виде артефактов (керамика, вооружение и конское снаряжение, предметы быта, культа и другое), наконец - о наглядном облике (образе) арысской культуры Южного Казахстана [11, с. 87137]. Была осуществлена этническая атрибуция арысской культуры с государством Кангюй (Кангха авестийских, Канцзюй китайских и Кангу-Тарбан древнетюркских источников). Удалось также установить полиэтничность Кангюй: в частности, выявлены позднесакс- кий, сарматский, сюннуский и собственно кангюйский этнические компоненты [11, с. 139-163].

Именно тогда в археологических материалах катакомбных погребений были зафиксированы артефактные комплексы, близкие по своим археологическим параметрам к памятникам сарматов Крыма, Северного Причерноморья, междуречья Волга - Дон, Южного Приуралья и Западного Казахстана [5]. На том этапе исследований были открыты несколько катакомб с полным набором погребальной атрибутики, указывающей на ее явно сарматское происхождение - например, комплекс кургана 3 могильника Каратобе [11, с. 53-56], кургана 15 могильника Алтынтобе [11, с. 63]. Последующие изыскания значительно расширили артефактный базис материалов сарматского облика на уровне археологических комплексов из погребений в катакомбах Южного Казахстана.

Это бронзовые дисковидные зеркала (с бортиком и умбоном, без ручки-штыря и с таковой); культовые предметы - алебастровые и меловые амулеты, курильницы; сложносоставные луки и наконечники стрел, украшения в виде ожерелий из стеклянных, пастовых, гагатовых и иных бус; зооморфные и амфоровидные подвески из фаянса и бронзы; наборные браслеты с использованием бус, раковин-каури, бронзовых колокольчиков и бубенчиков; элементы конского снаряжения подпружные железные пряжки, удила; клинковое оружие - железные мечи, кинжалы в сложноконструктивных ножнах; изделия в зве- 
рином и золото-бирюзовом стиле; тамгообразные знаки на керамике, близкие к сарматским знакам, и другое.

Данные комплексы в сочетании с конструкцией погребальных ям (Т-образные катакомбы с узкотраншейным ступенчатым дромосом, катакомбы с заплечиками), обрядом погребения и той реалией, что происхождение многих артефактов связано с регионами Северного Причерноморья, Крыма, Кавказа (а также - Египта и даже Западной Европы), говорили о том, что мы имеем дело либо с сарматами, либо с кругом племен сарматского облика. Обилие археологического материала, его качественные параметры не просто иллюстрировали импорт или товарный обмен в рамках торговли между традиционными сарматскими регионами на западе и автохтонными племенами Средней Азии и Южного Казахстана на востоке, а показывали стационарное проникновение сюда культурных традиций сарматов в виде артефактов, которые могли быть привнесены только их носителями.

Вновь сарматская проблематика зазвучала после того, когда в регионе начались масштабные работы по реализации программы «Археологические и письменные памятники государства Канцзюй (Кангюй) II в. до н. э. - IV в. н. э.» [13, с. 208-229]. В 20052009 гг. на городище Культобе I-IV в. н. э. было найдено уникальное письмо на керамических кирпичах-таблицах [12, с. 133-139; 28, p. $1006-1034 ; 29$, с. 153-171], и возникла необходимость более полно исследовать близлежащие к городищу крупные могильники с целью выяснения культурно-исторического фона, на котором возникло это письмо.

Начались раскопки могильников Культобе и Кылышжар, которые дали еще более значимые погребальные комплексы из катакомб, свидетельствующие о том, что какая-то часть (ветвь) сарматского союза на рубеже эр проникла на территорию Южного Казахстана и оставила здесь свои погребальные памятники [14, с. $138-144 ; 16$, с. 207-217]. Перечисленные исследования воплотились в серию публикаций, которые археологически зафиксировали присутствия сарматов в Южном Казахстане. Однако констатация этого факта не означает отсутствие проблем научного поряд- ка, связанных с сарматами в Южном Казахстане, - напротив, обозначились моменты, требующие более аргументированных заключений, уточнений и корректировок историкокультурного и хронологического характера в контексте сарматской тематики. В тезисном варианте уместно будет обратиться к нескольким ключевым проблемным моментам в этой сфере в свете новых археологических, нумизматических и палеолингвистических данных.

\section{Погребальная конструкция и обряд}

В Южном Казахстане преимущественно представлены Т-образные (Г-образные) катакомбы с длинным узкотраншейным дромосом и Т-образные катакомбы с дромосом с заплечиками.

Катакомбы первого типа трехчастные, включают длинный траншейного типа ступенчатый (иногда бесступенчатый) дромос-коридор; аркообразный в разрезе короткий по длине лаз; сводчатую прямоугольную (трапециевидную) в плане погребальную камеру с прямыми (иногда сглаженными) углами. Обычно катакомба вытянута с юга на север, уровень пола камеры и уровень пола лаза могут совпадать и не совпадать (то есть может фиксироваться или отсутствовать ступенька). Кроме того, место соединения дромоса с лазом заложено выкладкой из крупного прямоугольно-трапециевидного кирпича-сырца (рис. 1, 1, 3; 2, 1-3).

Катакомбы второго типа характеризуются: большим широким прямоугольным, напоминающим грунтовую яму дромосом; малым дромосом, выполненным как пандус с уклоном вглубь, в полу большого дромоса (в результате формируются так называемые заплечики); сводчатой полой погребальной камерой прямоугольной или овально-трапециевидной планировки; место соединения малого дромоса и камеры обычно тоже заложено кладкой из кирпича-сырца (рис. 1, 2). Все катакомбы находятся на значительной от дневной поверхности глубине, минимум от 3-3,5 м, максимум до 5,5-6,5 м, а размеры камеры (3,5 на 4,5 м) и высота ее свода (до 2 м) также могут быть значительными.

Археологические комплексы, близкие к сарматским, количественно зафиксированы преимущественно в катакомбах с дромосом с заплечиками (могильник Каратобе, Культо- 
бе, Кылышжар); обнаружены они также и в классических Т-образных катакомбах с узкотраншейным дромосом (могильники Ордабасы, Акбулактобе, Тулебайтобе II, Культобе и Кылышжар).

В катакомбах преобладают коллективные погребения (от двух до восьми костяков в погребальной камере) при наличии и одиночных захоронений. В случае с коллективными погребениями отмечен факт нескольких разновременных захоронений; при этом если «полезной площади» в камере не хватало, костные останки предыдущих покойников сдвигались от центра к стенкам камеры, а на освободившееся место клались новые усопшие. В этом плане катакомба «работала» как склеп, и в таком контексте понятен факт непересыпания насыпью кургана основных подземных конструкций катакомбы (дромос почти всегда находился за границей или кромкой насыпи): в древности ее эпизодически вскрывали и осуществляли новые погребения. Обряд погребения - трупоположение на спине в одиночном, парном и коллективном вариантах. Доминирует восточная ориентировка костяков, однако когда камера переполнена, в одном погребении наблюдается различная ориентировка костяков (восточная, западная, иногда - южная).

Другие ключевые особенности обряда погребения применительно к катакомбам в контексте сарматской тематики Южного Казахстана:

- костяки клались на плетеные камышовые маты или располагались на песчано-гравийной подсыпке с включениями угля; отмечено присутствие в камере плетеного из прутьев гробовища;

- одежда вместе с аксессуарами (пряжки, фибулы-застежки), а также украшениями (наборные ожерелья, браслеты) и другими значимыми предметами (зеркала, амулеты) помещалась в ногах погребенных;

- женские погребения в сравнении с мужскими сопровождал более богатый погребальный инвентарь, а в одиночных женских погребениях отмечено наличие оружия (наконечники стрел);

- «жертвенное мясо» в виде передней части туши овцы в погребальной камере; иногда вблизи находился небольшой железный нож;
- артефакты, связанные с культом огня или другими ритуальными действиями (керамические курильницы, меловые и алебастровые амулеты);

- наличие клинкового (железные мечи, кинжалы) и дистанционного (части лука, наконечники стрел) оружия; в одном случае найдены следы защитного доспеха (пластины железной катафракты);

- артефакты из серебра, сделанные в традициях звериного стиля сарматов, украшения в золото-бирюзовом и полихромном стиле [17, с. 139 , рис. $2,2-3]$.

«...Я далек от мысли всюду, где обнаружены подбойно-катакомбные погребения, видеть сарматов. Но в отдельных случаях сходство (материалов. - A. П.) настолько велико, что мы вправе отождествлять их с сарматами». Это мнение А.С. Скрипкина в отношении материалов могильников Лявандакский и Кую-Мазарский в Средней Азии [23, с. 48]. Между тем материалы погребальных памятников Южного Казахстана показывают, что катакомба не может выступать в роли этноопределяющего признака у номадов в силу того, что последние могли заимствовать эту конструкцию у автохтонного оседло-земледельческого народонаселения, которое традиционно практиковало катакомбы как семейные (родовые) склепы.

Так, например, сарматы на своих исконных этнических территориях хоронили преимущественно в прямоугольных, удлиненных грунтовых ямах (узких, средних, широких), в подбойных и квадратных ямах, ямах с заплечиками с использованием дерева, в небольшом количестве в несложных катакомбах [9, с. 178, 191; 6, с. 104-121). Однако почти полный сарматский археологический комплекс присутствуют в катакомбах Южного Казахстана [15, c. 207-217].

Судя по всему, часть кочевников по ряду причин (мобильность, уникальная социальная адаптация и быстрое восприятие новаций любого рода, в том числе в погребальной обрядности; критические условия ландшафтно-почвенного и природного порядка, когда создать полноценное традиционное погребальное сооружение на новом месте невозможно) при общем сохранении основных ритуальных действий могла заимствовать у оседло-земле- 
дельческих этносов как конструкцию, так и некоторую погребальную атрибуцию.

Свидетельством трансформаций в обрядности являются и новые функции курганной насыпи. Если на основных этнических территориях у сарматов под курганной насыпью фиксируется несколько погребальных сооружений, то значительная часть катакомб Южного Казахстана находится либо у кромки, либо вообще за пределами курганной насыпи, то есть налицо изменения семантической нагрузки кургана как солярного символа (или символа основного жилища кочевника, юрты). Подобная ситуация, когда погребальное сооружение не перекрывается сверху курганной насыпью, может иллюстрировать и практические цели - возможностью без особых трудовых затрат осуществить дополнительные погребения через дромос, который остается за пределами насыпи.

Судя по материалам сарматского историко-культурного облика из катакомб Южного Казахстана, можно говорить о том, что отношение номадов к погребальной конструкции, насыпному кургану, некоторой атрибутике (керамика) не было столь консервативным и стационарным явлением, как считалось ранее.

\section{Керамика}

Обязательным в погребальной обрядности катакомб Южного Казахстана является присутствие керамики. Обычно это высококачественная посуда столового и ритуального назначения местных гончаров, включающая такие типы керамики, как горшки, кувшины, фляги, чаши, кружки и курильницы, используемые в качестве погребального инвентаря. Керамика сделана из качественного теста с помощью быстро вращающегося круга, прекрасно обожжена в двухкамерных гончарных печах [10, с. 183-187] и декорирована ключевыми для арысской культуры приемами: станковое рифление, рельефно-выпуклые валики, покрытие ангобами различных цветов, лощение по ангобу, ангобные потеки [11, с. 93-94].

Однако наряду с автохтонной керамикой, в катакомбах с сарматской погребальной атрибуцией встречена посуда явно импортного производства, которая заметно вы- деляется по качеству выделки, обжига и декора от традиционной керамики Южного Казахстана I в. до н. э. - IV в. н. э. Это грушевидные горшки без ручек, аналогичной формы кувшины с выраженной прямо посаженной горловиной, крутыми плечиками (с вертикальными петлевидными ручками и без ручек), кружки банкообразной формы без ручек и грушевидной - с ручками на плечиках, а также архаичные чашевидные на высокой ножке-поддоне курильницы (с ручками и без таковых), украшенные «зубчиками» и рельефно-выпуклыми шишечками.

Вся керамика выполнена вручную из достаточно грубого теста, она кострового обжига, с закопченной (черной) внешней поверхностью, декор практически отсутствует: эпизодически встречается лощение по внешней поверхности кувшинов и прочерченный по сырой глине концентрический орнамент в виде «змейки» на горшках (рис. 3, 1-15).

Заметим, что керамическое производство качественной посуды широкого ассортимента с его трудоемкими циклами (подготовка хорошего теста, формовка изделий, обжиг в керамических печах) - это сложный и высокотехнологичный по тем временам процесс, мало совместимый с кочевым образом жизни. Поэтому номады Евразии всегда ценили керамику и использовали ее как в бытовых, так и ритуальных целях, поскольку сами изготовлять хорошего уровня керамические изделия не умели. Такой тезис прямо соотносится с мнением М.П. Абрамовой, которая пишет: «...собственно сарматская керамика... однообразна и бедна. Сарматы - кочевые племена, имевшие довольно низкий уровень развития материальной культуры, плохо развитое керамическое производство, незнакомое с гончарным кругом» $[1$, с. 48$]$.

По мнению А.С. Скрипкина, тенденция заимствования керамики у местного оседлоземледельческого населения характерна для сарматов Поволжья и Подонья [23, с. 48$]$. Аналогичная ситуация с керамикой из катакомб Южного Казахстана с материалами сарматского облика: комплекс качественной, прекрасно сделанной на быстровращающемся гончарном круге и богато декорированной столовой и ритуальной посуды почти всегда сопровождает подобные погребения. Более того, 
это явление настолько характерно, что можно говорить о существовании производственных центров, которые «обслуживали» прибывших в регион номадов поставками высококачественной керамики для погребальных нужд (об этом свидетельствует посуда, которая никогда не использовалась в быту, так как сразу после изготовления отправлялась в погребение в качестве инвентаря).

Между тем какую-то часть керамики, не требующую больших трудовых затрат и владения специфическими технологиями и необходимую им в быту и погребальной обрядности, номады вполне могли изготовлять самостоятельно (ручной лепки «...горшки и некоторые типы кувшинов») [25, с. 30]. Аналогичная ситуация с кухонной и ритуальной посудой ручной работы и открытого обжига явно импортного происхождения из катакомб арысской культуры: судя по всему, этот вид посуды мог быть сделан непосредственно сарматами и привнесен ими же в Южный Казахстан - тем более, что аналогии перечисленной выше керамике широко представлены в погребальных памятниках европейской и азиатской Сарматии [9, с. 181, табл. 74, 8, 10, 14 $16,23-24$, табл. $75,10,12,22,28 ; 24$, c. 24 32 , рис. 4,$4 ; 5,9$, рис. $7,11,14$, рис. $8,2,4 ; 25$, с. $37-42$, рис. $8,1,7,13,16,20-21$, рис. $9,14-$ $15,18-20,26,28,32,34]$.

\section{Знаки на керамике}

Тамгообразные знаки фиксируются на керамике арысской культуры Южного Казахстана достаточно часто. Более того, они позиционируются как один из специфических признаков этой культуры [11, с. 95-99]. Как правило, знаки наносились на керамику столового назначения, связанного с водой (кувшины, фляги, кружки), а также на хумы. Очевидно, что появление такой керамики в погребальной камере связано с традиционной обрядностью в рамках религиозного дуализма и веры в потустороннее существование. При этом сосуды имели «персональное» назначение (количество костяков и керамической посуды в погребении обычно совпадает).

Все знаки-тамги на керамической посуде из катакомб прочерчивались по сырой глине до обжига и декора изделия. Самые круп- ные, четко вычерченные знаки (до 20-24 см высотой) фиксируются на хумах. Более мелкие, но тоже хорошо прочерченные, - на посуде столового назначения. Обычно знакитамги у хумов отмечены на плечиках сосудов, ниже венчика; у посуды столового назначения - в районе вертикальной петлевидной ручки (на ручке сверху, под ручкой) или на тулове сосуда. При этом не всегда знаки наносились «правильно»: отмечено расположение знаков в наклонном по высоте (вправо - влево), перевернутом и горизонтальном положении (рис. 4, I, 1-8; II, 1-6).

Особенностью сарматских знаков-тамг из катакомб Южного Казахстана на хумах является то, что они имели специальное ритуальное предназначение в погребальной обрядности: эти сосуды сначала намеренно разбивали (раздавливали) на фрагменты, потом ими сплошным порядком или частично выкладывали пол камеры, на который затем клали усопших. Знаки-тамги демонстрировали отношение умерших к личному, родоплеменному, возможно, земельно-территориальному и к социальному рангу в иерархии номадов. Такая керамика специально заказывалась кочевым народонаселением Канцзюй-Кангюй, по желанию которого в оседло-земледельческих центрах профессиональные гончары изготавливали соответствующую посуду и наносили на нее знаки-тамги, призванные выполнить определенную миссию в потустороннем мире.

Этот тезис подтверждается находками хумов со знаками на городище Культобе, где такие сосуды специально фрагментировались, фрагменты собирались в одно место для последующей отправки к погребальным камерам катакомб близлежащего могильника. Пример тому - почти целый хум с сарматским знаком, куда складировали фрагменты от еще трех хумов (рис. 5, 1).

Многие знаки на керамике из катакомб Южного Казахстана имеют сарматское происхождение или связаны с традициями тамгопользования отдельных групп сарматского круга племен. Это иллюстрируют не только их иконография, функциональность, но и археологические комплексы сарматского облика, сопровождающие эти знаки. По графическому исполнению они близки к сарматским зна- 
кам Северного Причерноморья периода Боспорского царства и тамгам хорезмийских царей из «дома Чжаову» Средней Азии и представляют собой различные сочетания круга, Т-образных и усообразных компонентов [26, c. $28-30,38,42-43,47,57-58 ; 4$, c. $76-77$, табл. XII].

\section{Вопросы хронологии и датировки}

Опорными в этом плане являются несколько ключевых артефактов, которые в сочетании с обрядом и погребальным комплексом могут обозначить хронологию в рамках относительной датировки.

В частности, это:

- бронзовые дисковидные зеркала с ручкой-штырем, бортиком по краю и умбоном в центре декоративной поверхности. Такие зеркала характерны для погребений конца раннесарматской (прохоровской) культуры $[20$, с. 174 , табл. 69,35$]$ и для среднесарматской культуры $[25$, с. $89-97$; рис. 36 , 1-8; 9, с. 187-188];

- серебряная и бронзовая фибулы (одночленная фибула с многовитковой пружиной, коленчато-изогнутой пластинчатой овальнокаплевидной спинкой и завитком на конце сплошного приемника и классическая лучковая фибула). Такие фибулы бытовали в сарматской среде во второй половине I - начале II в. н. э. [7, с. 185,204 , табл. 98, 98а];

- серьги, выполненные в полихромном и золото-бирюзовом стиле. Прямых аналогий золотым серьгам с «сердцевидной» перегородчатой печаткой, заполненной голубой стекловидной пастой и украшенной по периметру зернью, найти не удалось, но подобный декоративный прием достаточно широко применялся в сакской культуре Казахстана IV-III вв. до н. э. [2, с. $133 ; 21$, с. 80-81, 116]. Что касается классической сердцевидной формы печатки, то этот мотив известен и в чисто сарматской среде. Например, рукоять и ножны парадного меча из Порогов (Северное Причерноморье, последняя четверть I в. н. э.) украшены золотыми декоративными накладками, включающими цепочку аналогичных сердцевидных печаток, причем - с бирюзовыми вставками [22, с. 36-37; рис. 22, 1, 3, 6, $7,9,10$, рис. $160 ; 18$, с. 72 , рис. 3,3$]$;
- кинжал с кольцевым навершием и прямым брусковидным перекрестием в сложноконструктивных ножнах (дерево, ткань, кожа, окрашенная в ярко-красный цвет). Подобное оружие отмечено у сарматов Северного Причерноморья в последних веках до нашей эры [9, с. 183, табл. 81, 21-26] и первых веках нашей эры $[22$, с. $32-39$, рис. $15,24,1]$. Отмечены они также в сарматских памятниках Поволжья и Приуралья последних веков до первых веков н. э. [27, с. 10];

- подвески в виде «кукиша», жука-скарабея, амфоровидные ребристые подвески и крупные круглые ребристые бусы (все египетского фаянса). Комплекс ярко иллюстрирует происхождение (Северное Причерноморье), время «жизни» (І в. до - I в. н. э.) и пути попадания к «варварским» племенам (в том числе сарматам) подобных украшений [3, с. 237-238, табл. CLVII, 7, 38, 51, 55, 57-58; 5, рис. 110 , 2-4]. Находки подвесок в виде «кукиша», скарабея и амфоровидных подвесок из египетского фаянса отмечены также в могильнике Тупхона I до н. э. - II в. н. э. [8, с. 58-61, рис. 19];

- серебряная пряжка, выполненная в зверином стиле (катакомба 10 могильника Кылышжар). Прямых аналогий зооморфной серебряной пряжке в виде головок грифа (грифона) найти не удалось, однако образ грифа (грифона) характерен для искусства скифов и савромато-сарматов начиная с середины I тыс. до н. э. и сохраняется в трансформированном «сарматском» варианте в более позднее время [20, с. 174 , табл. 66-67; 18, с. 73, рис. 3,1$]$.

В качестве косвенного хронологического фактора можно привлечь керамические курильницы, которые широко использовались в погребальной обрядности в сарматском обществе: независимо от форм, они фиксируются на всей территории расселения сарматов как культовые изделия, имеющие отношение к огню или иным особым погребальным действиям. Такие курильницы имели хождение в среднесарматское и позднесарматское время [9, с. 190 , c. 202 , табл. $80 ; 18$, с. 70 , рис. $2,6-11]$.

Как показывают вышеприведенные аналогии и хронологические выкладки, археологические комплексы с выраженным сарматским историко-культурным наполнением в катакомбах арысской культуры датируются 
последним веком до нашей эры - первыми веками нашей эры: именно в это время сарматы появляются в Южном Казахстане и интегрируются в состав государства Канцзюй (Кангюй).

Такой вывод подтверждают новые археологические, нумизматические и палеолингвистические источники, полученные из раскопок городища Культобе арысского в 2017 г., выступающие в роли дополнительного перекрестного хроноиндикатора. Речь идет об обнаружении в одном культурном слое кангюйского периода одновременно трех значимых находок: хума с сарматским знаком-тамгой (найден в вертикальном положении вкопанным по плечики в пахсовую платформу), медной монеты и фрагмента культобинского (содийского, кангюйского) письма на керамических кирпичах-таблицах.

Метрические и сюжетно-иконографические составляющие нумизматической находки позволяют связывать ее с одним из ранних чеканов Великой Кушанской империи (рис. 5, 2). Это монета из множественной эмиссии в недавнем прошлом безымянного кушанского правителя из серии «Soter Megas» с титулом «царь царей, великий спаситель», которая в свете новых данных принадлежит второму кушанскому царю, сыну основателя империи Куджулы Кадфиза, Вима I Такто, правившему в 80-90 гг. [19, с. 141-144].

Факт обнаружения монеты чекана Вима I Такто свидетельствует о том, что северо-восточные границы Великой Кушанской империи простирались в то время до Кангюй. Это объективно предполагает наличие экономических, культурных и, возможно, политических контактов между двумя мощными государствами древности. Если иметь в виду, что часть сарматов в то время входила в состав Кангюй (об этом свидетельствуют вышеприведенные материалы из катакомб Южного Казахстана), то совершенно отчетливо высвечивается тема, связанная с соприкосновением историко-культурных и иных традиций сарматского мира с Великой Кушанской империей.

Кроме того, находка этой монеты важна еще и тем, что она выступает в роли аргу- ментированного хроноиндикатора как для строительного горизонта кангюйского периода (хум со знаком; другой артефактный материал), так и для фрагмента культобинского (согдийского, кангюйского) письма на керамических кирпичах-таблицах, обнаруженного здесь же.

Фрагмент письма включает 10 хорошо читаемых, 6 частично восстанавливаемых знаков, оформленных в четыре строки (рис. 5, 3). Замечу, что уникальные эпиграфические артефакты в виде древней письменности на обожженных кирпичах-таблицах городища Культобе арысского - отдельная тема. В данном случае она интересует нас только в связи с упоминанием в одном из текстов этого письма «людей шатров» (то есть номадов), которые имели косвенную причастность к основанию города, причем в качестве этих «людей шатров» вполне могли выступать сарматы [28, p. 1006-1034].

В качестве заключения заметим, что приведенные выше материалы освещают только часть проблемных моментов в сарматской тематике региона Южного Казахстана, которая гораздо шире и насыщеннее. Такая ситуация определяется особой ролью Южного Казахстана как контактной зоны соприкосновения на Великом Шелковом пути культурных традиций многих этносов как с запада, так и с востока (в том числе - номадов). В этой связи новые данные археологического, палеолингвистического и нумизматического порядка ставят несколько стратегических вопросов, касающихся древней истории края и прямо связанных с сарматской проблематикой.

Вот некоторые из них: восточная версия генезиса и расширение границ сарматского мира; сарматский этнический компонент в составе государства Канцзюй (Кангюй); миграционные процессы (пути миграций сарматов в контексте направлений и времени) и юговосточная миграция сарматов в первые века нашей эры. Представляется, что решение этих вопросов - дело времени и позитивного международного сотрудничества ученых, занимающихся сарматской проблематикой и номадизмом в целом. 


\section{ПРИЛОЖЕНИЯ}


Рис. 1. Катакомбы Южного Казахстана. Внешний вид конструкции:

1 - Т-образная катакомба 20 центральной группы насыпей могильника Культобе;

2 - Т-образная катакомба 1 юго-западной группы насыпей могильника Кылышжар;

3 - Г-катакомба 24 центральной группы насыпей могильника Культобе

Fig. 1. Catacombs of Southern Kazakhstan. Appearance of the structure:

1 - T-shaped catacomb 20 of the central group of mounds of the burial ground Kultobe;

2 - T-shaped catacomb 1 of the South-Western group of mounds of the burial ground Kylyshzhar;

$3-\Gamma$ - shaped catalogob 24 of the central group of mounds of the burial ground Kultobe 


\section{ДИАЛОГ «ВОСТОК - ЗАПАД»}
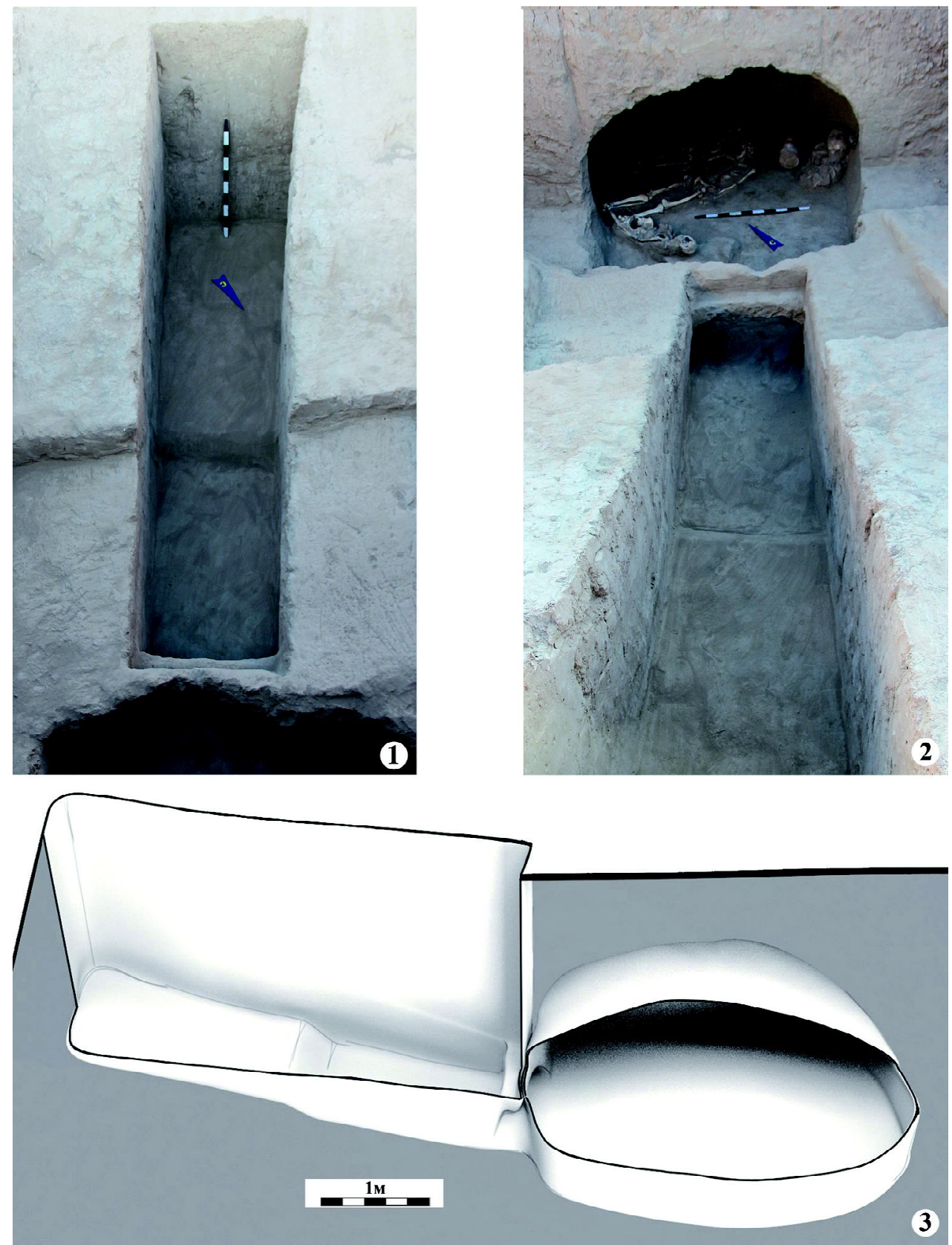

Рис. 2. Могильник Культобе. Восточная группа насыпей. Внешний вид катакомбы 3: 1-2 - фотография; 3 - в 3D формате (графика)

Fig. 2. The burial ground Kultobe. Eastern group of mounds. The appearance of catacomb 3: $1-2-$ photo; $3-3 \mathrm{D}$ format (graphics) 

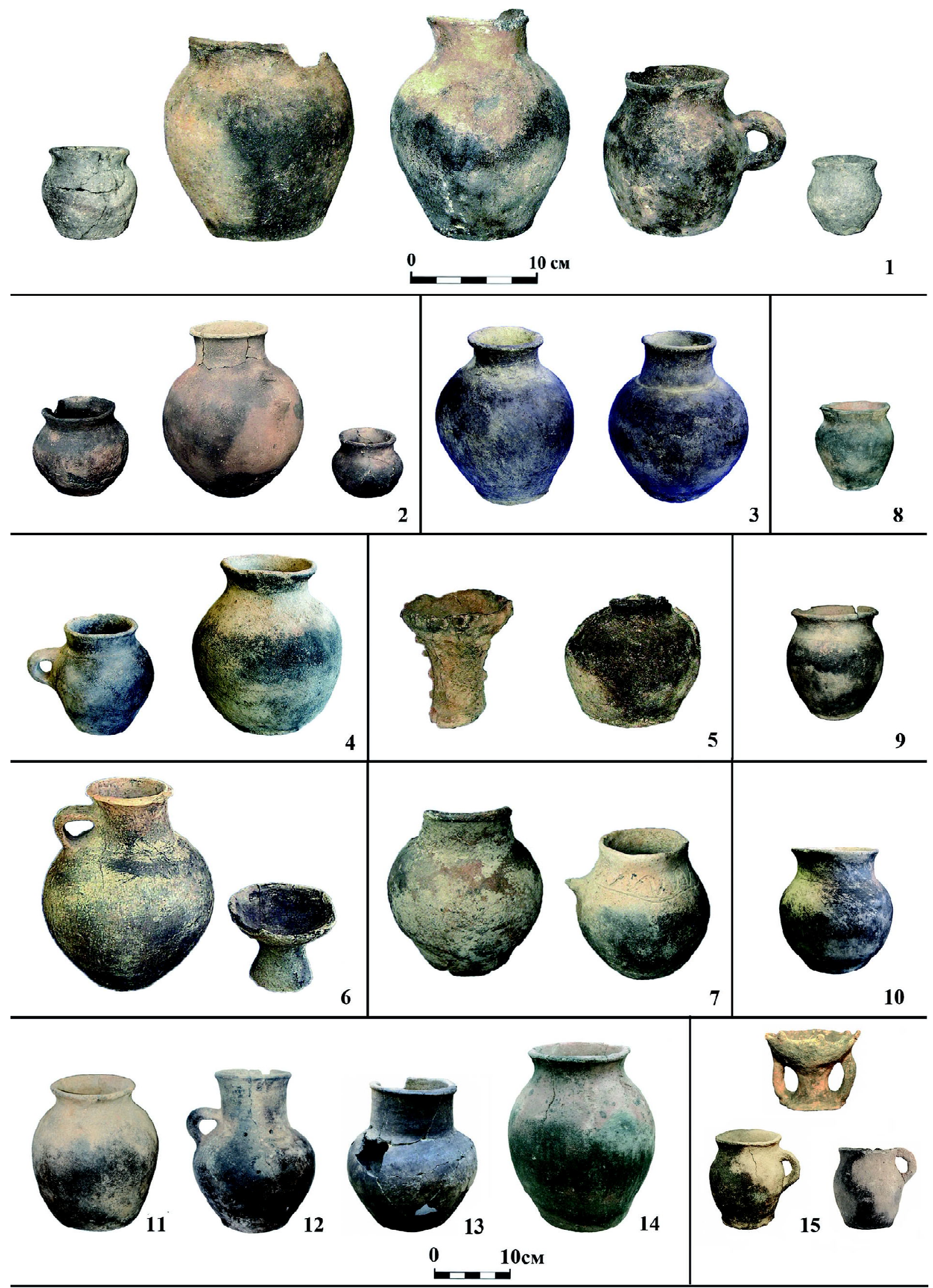

Рис. 3. Импортная керамика в катакомбах арысской культуры Южного Казахстана: 1 - керамический комплекс катакомбы 6 южной группы насыпей могильника Кылышжар; 2 - керамический комплекс погребения 1 могильника Бугуньский; 
3 - керамический комплекс катакомбы 6 центральной группы насыпей могильника Кылышжар; 4 - керамический комплекс катакомбы 9 центральной группы насыпей могильника Кылышжар;

5 - керамический комплекс катакомбы 8 центральной группы насыпей могильника Кылышжар;

6 - керамический комплекс катакомбы 3 центральной группы насыпей могильника Кылышжар;

7 - керамический комплекс катакомбы 1 южной группы насыпей могильника Кылышжар;

8 - кухонный горщок из катакомбы 12 центральной группы насыпей могильника Кылышжар;

9 - кухонный горшок из катакомбы 5 южной группы насыпей могильника Кылышжар;

10 - кухонный горшок из катакомбы 9 южной группы насыпей могильника Кылышжар;

11 - кухонный горшок из катакомбы 1 центральной группы насыпей могильника Кылышжар; 12 - кувшин из катакомбы 2 могильника Культобе 2;

13 - кувшин из катакомбы 6 восточной группы насыпей могильника Культобе;

14 - кухонный горшок из катакомбы 10 южной группы насыпей могильника Кылышжар;

15 - керамический комплекс катакомбы 8 восточной группы насыпей могильника Культобе

Fig. 3. Import ceramics in the catacombs of the Arys culture of Southern Kazakhstan:

1 - ceramic complex of catacomb 6 of the southern group of mounds of the burial ground Kylyshzhar; 2 - ceramic complex of burial 1 of the burial ground Bugunsky;

3 - the ceramic complex of catacomb 6 of the central group of mounds, the burial ground Kylyshzhar;

4 - the ceramic complex of catacomb 9 of the central group of mounds, the burial ground Kylyshzhar;

5 - the ceramic complex of catacomb 8 of the central group of mounds, the burial ground Kylyshzhar;

6 - the ceramic complex of catacomb 3 of the central group of mounds, the burial ground Kylyshzhar;

7 - the ceramic complex of catacomb 1 of the Southern group of mounds, the burial ground Kylyshzhar;

8 - a kitchen pot from catacomb 12 of the central group of mounds, the burial ground Kylyshzhar;

9 - a kitchen pot from catacomb 5 of the Southern group of mounds, the burial ground Kylyshzhar;

10 - a kitchen pot from catacomb 9 of the Southern group of mounds, the burial ground Kylyshzhar;

11 - a kitchen pot from catacomb 1 of the central group of mounds, the burial ground Kylyshzhar; 12 - a jug from catacomb 2, the burial ground Kultobe 2;

13 - a jug from catacomb 6 of the Eastern group of mounds, the burial ground Kultobe;

14 - a kitchen pot from catacomb 10 of the Southern group of mounds, the burial ground Kylyshzhar; 15 - the ceramic complex of catacomb 8 of the Eastern group of mounds, the burial ground Kultobe 


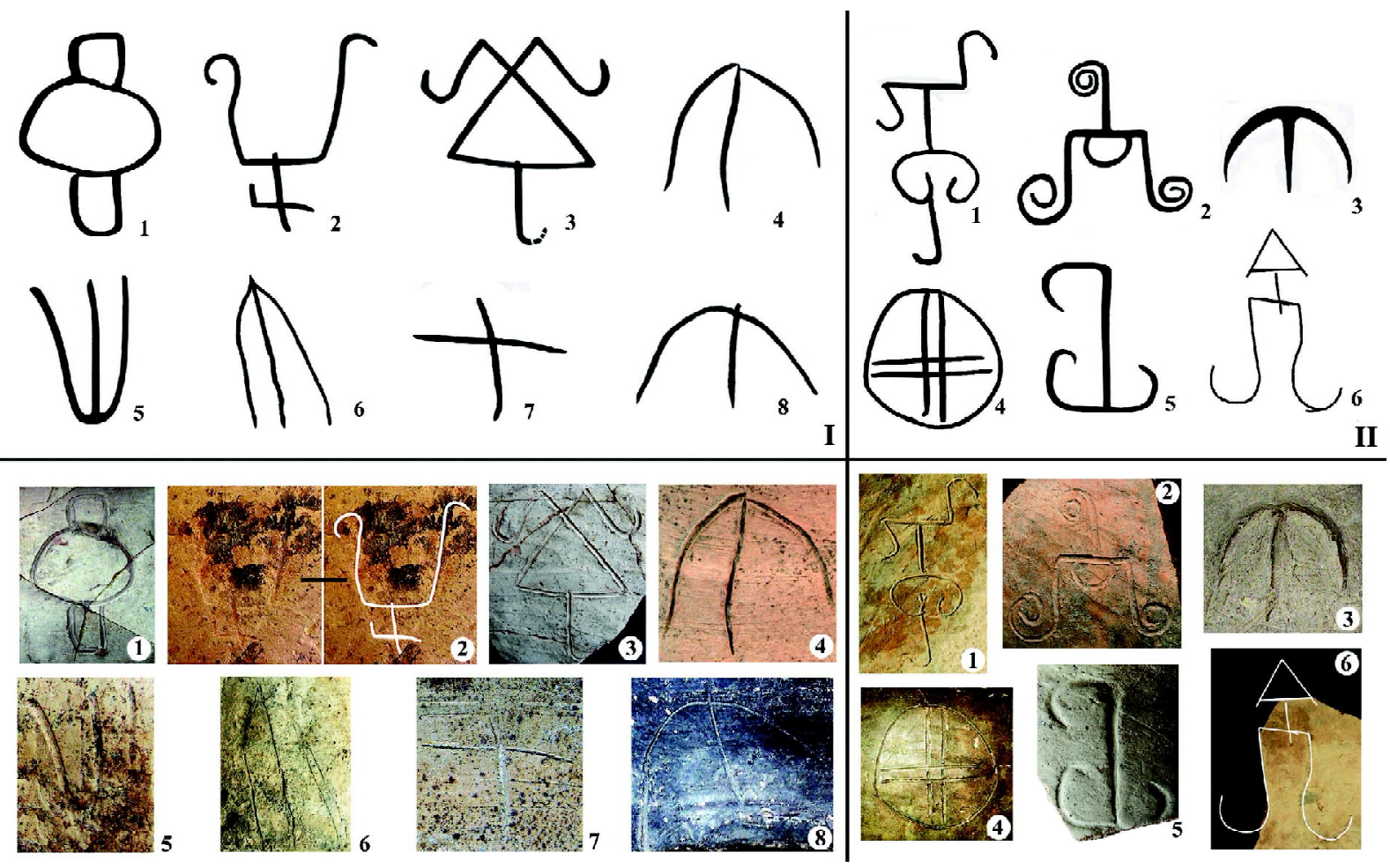

Рис. 4. Знаки на керамике из катакомб и ранних городищ Южного Казахстана:

I.1 - могильник Тулебайтобе 2, катакомба 15;

I.2 - могильник Культобе, центральная группа насыпей, катакомба 26; I.3 - могильник Культобе, центральная группа насыпей, катакомба 19; I.4, I.5 - могильник Культобе, восточная группа насыпей, катакомба 1; I.6, I.7 - могильник Культобе, восточная группа насыпей, катакомба 4; I.8 - могильник Кылышжар, центральная группа насыпей, катакомба 5;

II.1, II.2, II.4, II.6 - городище Культобе арысское; II.3 - городище Алтынтобе; II.5 - городище Караултобе

Fig. 4. Signs on ceramics from the catacombs and early settlements of Southern Kazakhstan:

I.1 - the burial ground Tulebaytobe 2, catacomb 15;

I. 2 - the burial ground Kultobe, central group of mounds, catacomb 26;

I.3 - the burial ground Kultobe, central group of mounds, catacomb 19;

I.4, I.5 - the burial ground Kultobe, Eastern group of mounds, catacomb 1;

I.6, I.7 - the burial ground Kultobe, Eastern group of mounds, catacomb 4;

I. 8 - the burial ground Kilyshjar, central group of mounds, catacomb 5;

II.1, II.2, II.4, II.6 - the ancient settlement Kultobe Arys; II.3 - the settlement Altintobe; II.5 - the ancient settlement Karaultobe 


\section{ДИАЛОГ «ВОСТОК - ЗАПАД»}
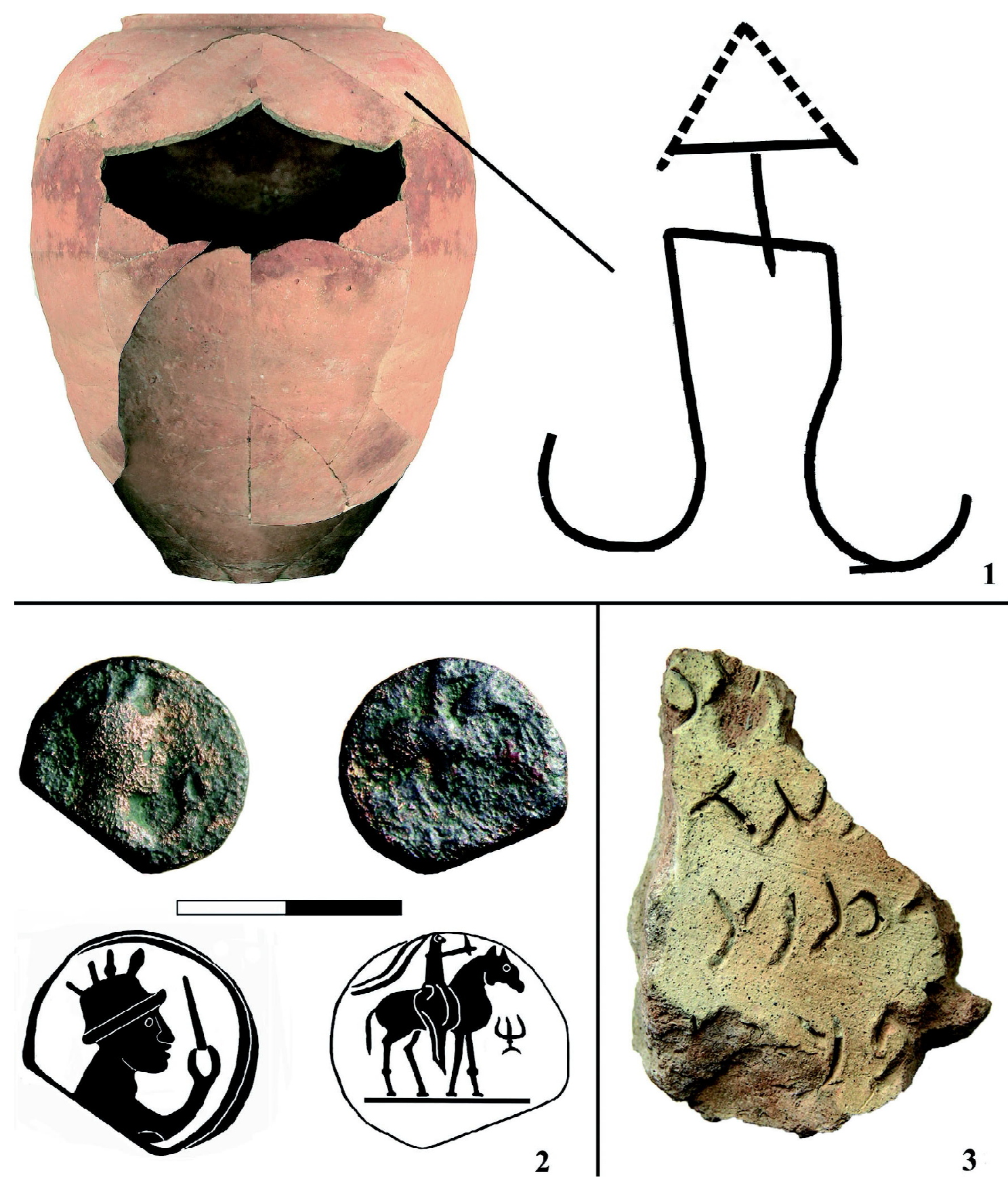

Рис. 5. Городище Культобе арысское:

1 - хум и тамгообразный знак на нем; 2 - кушанская монета; 3 - фрагмент культобинского (кангюйского) письма Fig. 5.The ancient settlement Kultobe Arysa:

1 - a khum with a tamga-shaped sign; 2 - a Kushan coin; 3 - a fragment of the Kultobin (Kangyu) letter 


\section{СПИСОК ЛИТЕРАТУРЫ}

1. Абрамова, М. П. К вопросу о связях населения Северного Кавказа сарматского времени / М. П. Абрамова // СА. - 1979. - № 2. - С. 31-50.

2. Акишев, К. А. Древнее золото Казахстана / К. А. Акишев, А. К. Акишев. - Алматы : Онер, 1983. $-214 \mathrm{c}$.

3. Алексеева, Е. М. Бусы и подвески/Е. М. Алексеева // Археология СССР. Античные государства Северного Причерноморья. - М. : Наука, 1984. C. 237-239.

4. Вайнберг, Б. И. Заметки о знаках и тамгах Монголии / Б. И. Вайнберг, Э. А. Новгородова // История и культура народов Средней Азии. - М. : Наука, 1976. - С. 69-77.

5. Зайцев, Ю. П. Неаполь Скифский (II в. до н. э. - ІІІ в. н. э.) / Ю. П. Зайцев. - Симферополь : Универсум, 2003. - $212 \mathrm{c}$.

6. Засецкая, И. П. «Диагональные погребения» Нижнего Поволжья и проблема определения их этнической принадлежности / И. П. Засецкая // Археологический сборник. - Ленинград : Авроpa, 1974. - С. 104-121.

7. Кропотов, В. В. Фибулы сарматской эпохи / В. В. Кропотов. - Киев : АДЕФ-Украина, 2010. $386 \mathrm{c}$.

8. Литвинский, Б. А. Культы и ритуалы Кушанской Бактрии (погребальный обряд) / Б. А. Литвинский, А. В. Седов. - М. : Наука, 1984. - 240 с.

9. Мошкова, М. Г. Среднесарматская культуpa / М. Г. Мошкова // Археология СССР. Степи европейской части СССР в скифо-сарматское время. М. : Наука, 1989. - С. 177-191.

10. Подушкин, Н. П. Гончарные печи раннеземледельческих поселений долины Арыси (Южный Казахстан) / Н. П. Подушкин // Археологические исследования в Казахстане. - Алма-Ата : Наука Каз. ССР, 1973. - С. 183-187.

11. Подушкин, А. Н. Арысская культура Южного Казахстана IV в. до н. э. - VI в. н. э. / А. Н. Подушкин. - Туркестан : Издат. центр МКТУ им. А. Яссави, 2000.-201 c.

12. Подушкин, А. Н. Новые памятники письменной культуры Южного Казахстана / А. Н. Подушкин // SHYGYS. - Алматы : Дайк-Пресс, 2005. № 2. - C. 133-139.

13. Подушкин, А. Н. Программа «Археологические и письменные памятники государства Канцзюй (Кангюй) II в. до н. э. - IV в. н. э.» : динамика реализации и некоторые итоги / А. Н. Подушкин // Изучение памятников археологии Павлодарского Прииртышья. - Павлодар : Павлодар. гос. ун-т им. С. Торайгырова, 2006. - Вып. 2. - С. 208-229.

14. Подушкин, А. Н. Некоторые итоги археологического исследования могильника Кылышжар в
2007 году / А. Н. Подушкин // Международная научная конференция «Кадырбаевские чтения - 2007». Актобе : Ин-т археологии им. А. Х. Маргулана МОН РК : Актюбинский гос. пед. ин-т, 2007. - С. 138-144.

15. Подушкин, А. Н. Сарматы в Южном Казахстане / А. Н. Подушкин // Древние культуры Евразии : материалы Междунар. науч. конф., посвящ. 100-летию А. Н. Бернштама. - СПб. : РАН, 2010. С. 207-217.

16. Подушкин, А. Н. Катакомбы могильника Кылышжар II в. до- III в. н. э. и сарматы на территории Южного Казахстана / А. Н. Подушкин // Материалы Междунар. науч. конф. «Кадырбаевские чтения 2012». - Актобе : Ин-т археологии им. А. Х. Маргулана КН МОН РК : Актюбинский гос. ун-т им. К. Жубанова, 2012. - С. 207-217.

17. Подушкин, А. Н. Раскопки катакомбы 1 восточной группы насыпей могильника Культобе в 2013 году / А. Н. Подушкин // Материалы IV Междунар. науч. конф. «Кадырбаевские чтения 2014» (9-10 окт. 2014 г.). - Актобе : Ин-т археологии им. А. Х. Маргулана КН МОН РК : Актюбинский гос. ун-т им. К. Жубанова, 2014. - С. 138144.

18. Подушкин, А. Н. Сарматская атрибутика в археологических комплексах катакомбных погребений арысской культуры Южного Казахстана (І в. до н. э. - III в. н. э.) / А. Н. Подушкин // Вестник Волгоградского государственного университета. Серия 4, История. Регионоведение. Международные отношения. - 2015. - № 5 (35). - C. 67-78. - DOI: https:// doi.org/ 10.15688/jvolsu4.2015.5.7.

19. Ртвеладзе, Э. В. Древние и раннесредневековые монеты историко-культурных областей Узбекистана. Т. I / Э. В. Ртвеладзе. - Ташкент : Отдел истории искусств НИИ искусствознания Академии художеств Республики Узбекистан, 2002. - 304 с.

20. Смирнов, К. Ф. Савроматская и раннесарматская культуры / К. Ф. Смирнов // Степи европейской части СССР в скифо-сарматское время. М. : Наука, 1989. - С. 165-177.

21. Самашев, 3. Древности Алматы / 3. Самашев, Ф. Григорьев, Г. Жумабекова. - Алматы : Археология, 2005. $-184 \mathrm{c}$.

22. Симоненко, А. В. Сарматские всадники Северного Причерноморья / А. В. Симоненко.-СПб. : Фак. филологии и искусств Санкт-Петербург. гос. ун-та : Нестор-История, 2010. - 328 с.

23. Скрипкин, А. С. Азиатская Сарматия во IIIV вв. / А. С. Скрипкин // СА. - 1982. - № 2. - С. 43-56.

24. Скрипкин, А. С. Нижнее Поволжье в первые века нашей эры / А. С. Скрипкин. - Саратов : Сарат. ун-т, 1984. - 150 с.

25. Скрипкин, А. С. Азиатская Сарматия. Проблема хронологии и ее исторический аспект / А. С. Скрипкин. - Саратов : Изд-во Сарат. ун-та, 1990. - 303 с. 
26. Соломоник, Э. И. Сарматские знаки Северного Причерноморья / Э. И. Соломоник. - Киев : Изд-во Академии наук УССР, 1959. - 179 с.

27. Хазанов, А. М. Очерки военного сарматов / А. М. Хазанов. - М. : Наука, 1971. - 172 с.

28. Sims-Williams, N. Les plus anciens monuments de la langue sogdienne: les inscriptions de Kultobe au Kazakhstan / N. Sims-Williams, F. Grenet, A. Podushkin // Academie des Inscription \& Belles. Paris : Diffusion de Boccard, 2007. - P. 1006-1034.

29. Sims-Williams, N. The sogdian inscriptions of Kultobe: text, translation and linguistic commentary / N. Sims-Williams // Труды Центрального музея. Алматы : Балалар эдебиеті, 2009. - Т. II. - С. 153-171.

\section{REFERENCES}

1. Abramova M.P. K voprosu o svyazyakh naseleniya Severnogo Kavkaza sarmatskogo vremeni [On the Issue of the Connections of the Sarmatian Population of the North Caucasus]. Sovetskaya arkheologiya [Soviet Archaeology], 1979, no. 2, pp. 31-50.

2. Akishev K.A., Akishev A.K. Drevnee zoloto Kazakhstana [The Ancient Gold of Kazakhstan]. Almaty, Oner Publ., 1983. 214 p.

3. Alekseyeva E.M. Busy i podveski [Beads and Pendants]. Arkheologiya SSSR. Antichnye gosudarstva Severnogo Prichernomorya [Archaeology of the USSR. Ancient States of the Northern Black Sea Region]. Moscow, Nauka Publ., 1984, pp. 237-239.

4. Vainberg B.I, Novgorodova E.A. Zametki o znakakh i tamgakh Mongolii [Notes on the Signs and Tamgas of Mongolia]. Istoriya i kultura narodov Sredney Azii [History and Culture of the Peoples of Central Asia]. Moscow, Nauka Publ., 1976, pp. 69-77.

5. Zaytsev Yu.P. Neapol Skifskiy (II v. do n. e.III v. n.e.) [Naples Scythian (the $2^{\text {nd }}$ century $\mathrm{BC}-3^{\text {rd }}$ century AD)]. Simferopol, Universum Publ., 2003. $212 \mathrm{p}$.

6. Zasetskaya I.P, 1974. «Diagonalnye pogrebeniya» Nizhnego Povolzhya i problema opredeleniya ikh etnicheskoy prinadlezhnosti ["Diagonal Burials" of the Lower Volga region and the Problem of Determining Their Ethnicity]. Arkheologicheskiy sbornik [Archaeological Collection]. Leningrad, 1974, pp. 104-121.

7. Kropotov V.V. Fibuly sarmatskoy epokhi [Fibulae of the Sarmatian Epoch]. Kiev, ADEF-Ukraina Publ., 2010. 383 p.

8. Litvinsky B.A, Sedov A.V. Kulty i ritualy Kushanskoy Baktrii (pogrebalnyy obryad) [Cults and Rituals of the Kushan Bactria (Funeral Rite)]. Moscow, Nauka Publ., 1984. 240 p.
9. Moshkova M.G. Srednesarmatskaya kultura [Middle-Sarmatian Culture]. Arkheologiya SSSR. Stepi evropeyskoy chasti SSSR v skifo-sarmatskoe vremya [Archaeology of the USSR. Steppes of the European Part of the USSR in the Scythian-Sarmatian Time]. Moscow, Nauka Publ., 1989, pp. 177-191.

10. Podushkin N.P. Goncharnye pechi rannezemledelcheskikh poseleniy doliny Arysi (Yuzhnyy Kazakhstan) [Pottery Furnaces of Early Agricultural Settlements of the Arysi Valley (Southern Kazakhstan)]. Arkheologicheskie issledovaniya $v$ Kazakhstane [Archaeological Research in Kazakhstan]. Alma-Ata, Nauka Kaz. SSR Publ., 1973, pp. 183-187.

11. Podushkin A.N. Arysskaya kultura Yuzhnogo Kazakhstana IV v. do n. e. - VI v. n. e. [The Arys Culture of Southern Kazakhstan in the $4^{\text {th }} \mathrm{c}$. BC $-6^{\text {th }} \mathrm{c}$. AD]. Turkestan, MKTU im. AYassavi Publ., 2000. 201 p.

12. Podushkin A.N. Novye pamyatniki pismennoy kultury Yuzhnogo Kazakhstana [New Monuments of Written Culture of Southern Kazakhstan]. SHYGYS. Almaty, Dyke-Press Publ., 2005, no. 2, pp. 133-139.

13. Podushkin A.N. Programma «Arkheologicheskie i pismennye pamyatniki gosudarstva Kantszyuy (Kangyuy) II v. do n. e. - IV v. n. e.»: dinamika realizatsii i nekotorye itogi [The Program 'Archaeological and Written Monuments of the State Kangju of the $2^{\text {nd }}$ century BC $4^{\text {th }}$ centuryAD': Dynamics of Implementation and Results]. Izuchenie pamyatnikov arkheologii Pavlodarskogo Priirtyshya. Pavlodar, Pavlodarskiy gos. un-t im. S. Toraygyrova, 2006, iss. 2, pp. 208-229.

14. Podushkin A.N. Nekotorye itogi arkheologicheskogo issledovaniya mogilnika Kylyshzhar v 2007 godu [Some Results of the Archaeological Research of the Kylyshzhar Burial Ground in 2007]. Materialy mezhdunarodnoy nauchnoy konferentsii "Kadyrbaevskie chteniya 2007» [Proceedings of the International Academic Conference 'Kadyrbaev Readings 2007']. Aktobe, Institut arkheologii im. A.Kh. Margulana MON RK; Aktyubinskiy gos. ped. in-t, 2007, pp. 138-144.

15. Podushkin A.N. Sarmaty v Yuzhnom Kazakhstane [The Sarmatians in Southern Kazakhstan]. Drevnie kultury Evrazii. Materialy mezhdunarodnoy nauchnoy konferentsii, posvyashchennoy 100-letiyu A.N. Bernshtama [Ancient Cultures of Eurasia. Proceedings of the International Academic Conference Dedicated to the 100th Anniversary of A.N. Bernshtam]. Saint Petersburg, RAN Publ., 2010. pp. 207-217.

16. Podushkin A.N. Katakomby mogilnika Kylyshzhar II v. do n.e. - III v. n. e. i sarmaty na territorii Yuzhnogo Kazakhstana [Catacombs of the Burial Ground Kilyshjar of the $2^{\text {nd }} c . B C-3^{\text {rd }} c$. AD, and Sarmatians on the Territory of Southern Kazakhstan]. 
Materialy mezhdunarodnoy nauchnoy konferentsii «Kadyrbaevskie chteniya 2012» [Proceedings of the International Academic Conference 'Kadyrbaev Readings 2012']. Aktobe, Institut arkheologii im. A.Kh. Margulana MON RK; Aktyubinskiy gos. un-t im. K. Zhubanova, 2012, pp. 207-217.

17. Podushkin A.N. Raskopki katakomby 1 vostochnoy gruppy nasypey mogilnika Kultobe $\mathrm{v}$ 2013 godu [Excavations of the catacomb of the eastern group of embankments of the cemetery Kultob in 2013]. Materialy IV mezhdunarodnoy nauchnoy konferentsii «Kadyrbaevskie chteniya 2014» (910 oktyabrya 2014 goda) [Proceedings of the International Academic Conference 'Kadyrbaev Readings 2014' (October 9-10, 2014)]. Aktobe, Institut arkheologii im. A.Kh. Margulana MON RK; Aktyubinskiy gos. un-t im. K. Zhubanova, 2014, pp. 138-144.

18. Podushkin A.N. Sarmatskaya atributika v arkheologicheskikh kompleksakh katakombnykh pogrebeniy arysskoy kultury Yuzhnogo Kazakhstana (I v. don. e. - III v. n. e.) [Sarmatian Attributes in Archaeological Complexes of Catacomb Burials of the Arys Culture of Southern Kazakhstan (the $1^{\text {st }} \mathrm{c}$. BC- $3^{\text {rd }}$ c. AD)]. Vestnik Volgogradskogo gosudarstvennogo universiteta. Seriya 4, Istoriya. Regionovedenie. Mezhdunarodnye otnosheniya [Science Journal of Volgograd State University. History. Area Studies. International Relations], 2015, no. 5(35), pp. 67-78. DOI: https://doi.org/10.15688/ jvolsu4.2015.5.7.

19. Rtveladze E.V. Drevnie i rannesrednevekovye monety istoriko-kulturnykh oblastey Uzbekistana. Tom I [Ancient and Medieval Coins of Historical and Cultural Regions of Uzbekistan. Vol. 1]. Tashkent, Otdel istorii iskusstv NII Iskusstvoznaniya Akademii khudozhestv Respubliki Uzbekistan, 2002. 304 p.

20. Smirnov K.F. Savromatskaya i rannesarmatskaya kultury [Sauromatian and Early Sarmatian Cultures]. Stepi evropeyskoy chasti SSSR v skifo-sarmatskoe vremya [Steppes of the European Part of the USSR in the Scythian-Sarmatian Time]. Moscow, Nauka Publ., 1989, pp. 165-177.

21. Samashev Z., Grigoryev F., Zhumabekova G. Drevnosti Almaty [Antiquities of Almaty]. Almaty, Arkheologiya Publ. 2005. 184 p.

22. Simonenko A.V. Sarmatskie vsadniki Severnogo Prichernomorya [Sarmatian Horsemen of the Northern Black Sea Region]. Saint Petersburg, Izd-vo SPGU; Nestor-Istoriya Publ., 2010. 328 p.

23. Skripkin A.S. Aziatskaya Sarmatiya vo II IV vv. [Asian Sarmatia in the $2^{\text {nd }}-4^{\text {th }}$ cc. AD]. Sovetskaya arkheologiya [Soviet Archaeology], 1982, no. 2, pp. 43-56.

24. Skripkin A.S. Nizhnee Povolzhye v pervye veka nashey ery [The Lower Volga Region in the First Centuries of Our Era]. Saratov, Izd-vo SGU, 1984. $150 \mathrm{p}$.

25. Skripkin A.S. Aziatskaya Sarmatiya. Problema khronologii i ee istoricheskiy aspekt [Asian Sarmatia. The Problem of Chronology and Its Historical Aspect]. Saratov, Izd-vo SGU, 1990. 303 p.

26. Solomonik E.I. Sarmatskie znaki Severnogo Prichernomorya [Sarmatian Signs of the Northern Black Sea Region]. Kiev, Izd-vo AN SSSR 1959. 179 p.

27. Khazanov A.M. Ocherki voennogo dela sarmatov [Essays on the Military Affairs of Sarmatians]. Moscow, Nauka Publ., 1971. 172 p.

28. Sims-Williams N., Grenet F., Podushkin A. Les plus anciens monuments de la langue sogdienne: les inscriptions de Kultobe au Kazakhstan. Paris, Academie des Inscription \& Belles, 2007, pp. 1006-1034.

29. Sims-Williams N. The sogdian inscriptions of Kultobe: text, translation and linguistic commentary. Trudy Tsentralnogo Muzeya [Proceedings of the Central Museum]. Almaty, Balalar edebieti Publ., 2009, vol. 2, pp. 153-171.

\section{Information about the Author}

Aleksandr N. Podushkin, Doctor of Sciences (History), Professor, Department of History of Kazakhstan and World History, South Kazakhstan State Pedagogical Institute, Baytursynova St., 13, 160017 Shymkent, the Republic of Kazakhstan, p_a_n_alex@mail.ru, https://orcid.org/0000-0003-1603-1373

\section{Информация об авторе}

Александр Николаевич Подушкин, доктор исторических наук, профессор кафедры истории Казахстана и мира, Южно-Казахстанский государственный педагогический институт, ул. Байтурсынова, 13, 160017 г. Шымкент, Республика Казахстан, p_a_n_alex@mail.ru, https:// orcid.org/0000-0003-1603-1373 